\title{
Theoretical Study by Density Functional Theory Method (DFT) of Stability, Tautomerism, Reactivity and Prediction of Acidity of Quinolein-4-One Derivatives
}

\author{
Affoué Lucie Bédé ${ }^{*}$, Amon Benjamine Assoma ${ }^{1}$, Kicho Denis Yapo ${ }^{1}$, \\ Mamadou Guy-Richard Koné2, Soleymane Koné1, Mawa Koné1, Boka Robert N'Guessan1, \\ El-Hadji Sawaliho Bamba' ${ }^{1}$ \\ ${ }^{1}$ Laboratoire de Chimie Organique Structurale, Université Félix Houphouët-Boigny, Abidjan, Côte d'Ivoire \\ ${ }^{2}$ Laboratoire de Thermodynamique et de Physico-Chimie du Milieu, Université Nangui Abrogoua, Abidjan, Côte d'Ivoire \\ Email: *lucie.bagayoko@gmail.com
}

How to cite this paper: Bédé, A.L., Assoma, A.B., Yapo, K.D., Koné, M.G.-R., Koné, S., Koné, M., N'Guessan, B.R. and Bamba, E.-H.S. (2018) Theoretical Study by Density Functional Theory Method (DFT) of Stability, Tautomerism, Reactivity and Prediction of Acidity of Quinolein-4-One Derivatives. Computational Chemistry, 6 , 57-70.

https://doi.org/10.4236/cc.2018.63005

Received: May 11, 2018

Accepted: July 22, 2018

Published: July 25, 2018

Copyright $\odot 2018$ by authors and Scientific Research Publishing Inc. This work is licensed under the Creative Commons Attribution International License (CC BY 4.0).

http://creativecommons.org/licenses/by/4.0/

\begin{abstract}
A theoretical study of the reactivity of quinoline-4-one derivatives is undertaken in order to understand the involved mechanisms. The calculations were carried out in gas phase and in N, N-Dimethylformamide (DMF) solution. The Density Functional Theory (DFT) with B3LYP functional associated to 6-311G (d) and 6-311+G (d) bases is used to perform these calculations. The results of the thermodynamic parameters showed that there is an equilibrium relation between the different tautomers. This equilibrium can be used to explain the failure to obtain tetrahydroquinoline from

5,8-dimethoxy-quinolin-4-one. Reactivity analysis from Frontier Molecular Orbitals theory and Fukui function calculations revealed that ketone forms are less reactive than enol ones. The methoxyl substituent decreases the acidity of the nitrogen and oxygen atoms of quinolin-4-one while the bromine increases the acidity of the same sites. These results foresee that nitrogen deprotonation in the case of the brominated compound is easier than in the case of methoxylated ones.
\end{abstract}

\section{Keywords}

Quinolein-4-One, Tautomers, Equilibrium Constants, Global Descriptors, Dual Descriptors

\section{Introduction}

Life expectancy, as well as pollution of various kinds, associated with new tech- 
nologies and different risk factors such as alcohol or tobacco, increase in the number of pathologies. Cancer is found among these pathologies [1]. Thus, many researchers focused themselves on new treatments finding. These researches help them to discover, the very interesting role of quinone compounds. They are often found in biological systems such as photosynthetic or enzymatic systems, and in chemistry (oxidation, conductive polymers, etc.) [2] [3] [4]. These molecules are present in many structures with high antitumoral potential [5] [6] [7] [8] [9]. According to the usefulness of the biological interest of this nucleus, several ways of synthesis have been invented in order to obtain it [6] [7] [8] [10] [11] [12] [13]. Quinones have the same basic motif which is cyclohexadiene type. They possess units having exocyclic double bonds, giving them a large number of physicochemical properties. The para-dimethoxyl tetrahydroquinoline ring is an essential element for the synthesis of these quinones. Thus, 5,8-dimethoxy-4,4-dimethyltetrahydroquinoline is presented as a key intermediate which is necessary for the synthesis of these quinones. Although that of tetrahydroquinoline is described, many synthetic ways have been envisaged with the purpose of its elaboration [11] [14] [15] [16]. Moreover, it has been shown that obtaining this key nucleus from 5,8-dimethoxy-quinolin-4-one by using the conditions of Reetz does not give the desired product [17]. These experimental studies have also shown that the reduction of the double bonds' number of quinolin-4-one is made in order to obtain dihydroquinolin-4-one but it has not been observed [18]. A theoretical study of quinolein-4-one derivatives is therefore undertaken in order to try to understand and predict the stability and reactivity of these compounds. The calculations are carried out in the gaseous phase and in $\mathrm{N}$, $\mathrm{N}$-dimethylformamide (DMF) solution with the functional B3LYP of the DFT method associated to the following bases 6-311G (d) and 6-311+G (d). The experimental difficulties evoked in obtaining 5,8-dimethoxy-4,4-dimethyltetrahydroquinoline from quinoline lead us to envisage the theoretical calculation of enthalpies of formation, enthalpies of reaction and free reaction enthalpies. The equilibrium constants are determined. Currently, the method of functional density theory (DFT) has been accepted as a popular approach for the calculation of the structural characteristics and energies of molecules by the community [19] and for the efficiency and accuracy of the evaluation of molecular properties [20]. This work aims to determine theoretically the preferred sites of electrophilic and nucleophilic attack on the aromatic carbon atoms and heteroatoms contained in the benzimidazolyl nucleus by different quantum chemistry methods. The molecular structures of the tautomers of quinoline derivatives studied are shown in Figure 1 and Figure 2. Figure 1 shows the two studied tautomeric forms; that is, ketone and enol forms. As for Figure 2, it shows the ketone tautomers (Q-4-one, DMQ and DBrQ) and enol (Q-4-hydroxy, DMHQ and DBrHQ).

\section{Material and Methods}

\subsection{Level of Calculation Theory}

Theoretical calculations are made by using the software called Gaussian 03 [21]. 


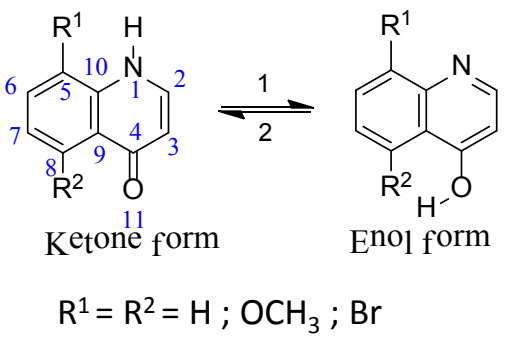

Figure 1. Keto-enol equilibrium in quinolin-4-one and atom numbers. The direction 1 is the equilibrium frome keto to enol and direction 2 is enol to keto.<smiles>O=c1cc[nH]c2ccccc12</smiles>
O (Q-4-one)

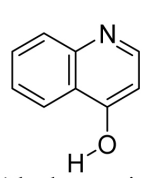

droxyquinoline (Q-4-hydroxy)

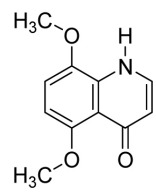

(DMQ)

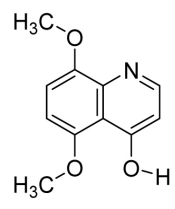

(DMHQ)

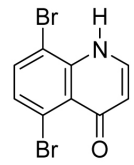

(DBrQ)

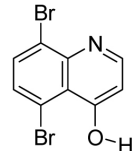

xy-4-hydroxyquinoline (DBrHQ)

Figure 2. Structures of tautomers of quinoline-4-one studied derivatives.

The different molecular structures have been optimized using the Functional Density Theory (DFT) [22] [23] [24]. The level of calculation used is B3LYP associated with bases $6-311 \mathrm{G}(\mathrm{d})$ and $6-311+\mathrm{G}(\mathrm{d})$. The calculations are carried out gaseous phase and solution. N, N-Dimethylformamide (DMF) being one of the solvents used for the synthesis of these quinolines [18], the calculations in solution are thus carried out in DMF. The Polarized Continuum Model (PCM) [25] [26] is taken as a solvation model. The optimization of the molecular geometries is followed by calculations of vibration frequencies at the same level of the theory in order to verify that the structures obtained are minimal.

\subsection{Thermodynamic Parameters of Reaction}

Knowledge of variations in energy contributions to internal energy which occurs between the products and the reagents helps to characterize energetically a chemical reaction. For a given energy parameter $X$, its variation is determined according to the following relation (1):

$$
\Delta_{r} X=\sum X(\text { products })-\sum X(\text { reactants })
$$

The thermodynamic determined quantities in this study are the reaction enthalpies $\left(\Delta_{r} H\right)$, the reaction free enthalpies $\left(\Delta_{r} G\right)$ and the equilibrium constants $\left(K_{e q}\right)$. These quantities are calculated by using relations (2) and (3) below:

$$
\begin{aligned}
& \Delta_{r} G=\sum \Delta_{f} G \text { (Products) }-\sum \Delta_{f} G \text { (Reactants) } \\
& \Delta_{r} H=\sum \Delta_{f} H \text { (Products) }-\sum \Delta_{f} H \text { (Reactants) }
\end{aligned}
$$

The equilibrium constant denoted $K_{e q}$ characterizes the equilibrium state of a chemical reaction. The value of the equilibrium constant depends solely on the considered chemical reaction and the temperature. In this work, the equilibrium constants are determined at $298 \mathrm{~K}$ from the following relation: 


$$
K_{e q}=\exp ^{\left(-\Delta_{r} G(T) / R T\right)}
$$

\subsection{Reactivity Parameters Derived from Conceptual DFT}

The Frontier Molecular Orbital (FMO) theory allows to understand the chemical reactivity. In particular, the prediction of the acidity of the different tautomers is made from the calculation of the deprotonation energies. The study of the reactivity of these molecules is carried out by taking into account the FMO [27]. This theory indicates the ease with which a molecule can be transformed or can react with other molecules. It gives a prediction of the excitation properties of a molecule. As a result, it constitutes quantum parameters for the determination of molecular reactivity [28] [29]. The smaller the energy gap between the HOMO and LUMO orbitals, the easier the molecule can be excited. Similarly a large gap HOMO-LUMO indicates a high stability of the studied molecule which implies its low reactivity during chemical reactions. The condensed Fukui functions are obtained using the Yang and Mortier procedure [30] [31] [32] based on the finite difference method. The different values of local descriptors are calculated from equations (4) and (5) below:

$$
\begin{aligned}
& f_{k}^{+}=q_{k}(N+1)-q_{k}(N) \\
& f_{k}^{-}=q_{k}(N)-q_{k}(N-1)
\end{aligned}
$$

where: $q_{k}(N)$ : Electronic population of the atom $k$ in the neutral form; $q_{k}(N+1)$ : Electronic population of the atom $k$ in the anionic form; $q_{k}(N-1)$ : Electronic population of the atom $k$ in the cationic form.

We can gather all the information contained in the two Fukui functions in a single function called dual descriptor. This function is represented by expression (6) which is below.

$$
\Delta f=f_{k}^{+}-f_{k}^{-}
$$

where $\Delta f$ is a function which represent the reactivity of the molecule, it is positive in the electrophilic areas and negative in the nucleophilic ones [33].

The chemical potential $\mu$ measures the tendency of the electron cloud to escape from the molecule. It is a global property of the molecular system which is equal to the slope of the total electronic energy $E$. This energy is a function of the number of electrons $N$ with an external potential $\mathrm{V}$ (r) constant. The studied parameter corresponds to the opposite of the electronegativity $\chi$ as defined by Pauling and Mulliken [34] [35]. This parameter is determined by the relation below (7)

$$
\mu=\left(\frac{\partial E}{\partial N}\right)=-\chi
$$

$\mu$ can be expressed as a function of the ionization potential IP and the electronic affinity EA and it is calculated by using the following relation (8).

$$
\mu=-\frac{\mathrm{IP}+\mathrm{EA}}{2}=-\chi
$$


The hardness $\eta \eta$ is determined from the first derivative of the chemical potential. And it must be noted that the softness $S$ is the inverse of the hardness [36] [37]. They are given by the following relation (9)

$$
\eta=\left(\frac{\partial \mu}{\partial N}\right)=\left(\frac{\partial^{2} E}{\partial E^{2}}\right)=\frac{1}{S}
$$

According to the theory of acids and bases, developed by Pearson [38], these quantities can be expressed as a function of both the Ionization Potentials (IP) and Electronic Affinity (EA). It permits to determine the relation (10)

$$
\eta=\frac{1}{S}=(\mathrm{IP}-\mathrm{EA}) / 2
$$

In order to characterize other electronic behaviors of the systems, we have interested ourselves to other descriptors such as the electrophile index $\omega$ which evaluate the ability of a molecule to generate an electron transfer. It is calculated according to the following formula [39].

$$
\omega=\frac{\mu^{2}}{2 \eta}=\frac{\chi^{2}}{2 \eta}
$$

These descriptors can be calculated in a very simple way in the framework of Koopmans' approximation [40] according to which:

$$
\mathrm{IP}=-E_{\mathrm{HOMO}} \text { and } \mathrm{EA}=-E_{\mathrm{LUMO}}
$$

$E_{\text {номо }}$ and $E_{\text {LUMо }}$ are the energies of the HOMO and LUMO orbitals.

\subsection{Parameters of Tautomers Acidity Prediction}

De protonation energies are widely used for the prediction of Brönsted acidity in gaseous and aqueous phases [41] [42] [43] [44]. The deprotonation reaction is defined by the following relationship (12).

$$
A H \rightarrow A^{-}+H^{+}
$$

The Gibbs energy $\Delta H_{0}^{298}$ of the protonic abstraction reaction is as follows (13):

$$
\Delta G_{0}^{298}=\Delta H_{0}^{298}-T \Delta S_{0}^{298}
$$

The contribution of entropy is given by the expression (14):

$$
-T \Delta S_{0}^{298}=-T\left[S\left(A^{-}\right)+S\left(H^{+}\right)-S(A H)\right]
$$

For a temperature of $T=298 \mathrm{~K}$ at standard pressure, the second term $T S\left(H^{+}\right)=32.5 \mathrm{Kj} \cdot \mathrm{mol}^{-1}$ gives the expression (15) [42] [43].

$$
\Delta G_{0}^{298}=\Delta H_{0}^{298}-T\left[S\left(A^{-}\right)-S(A H)\right]-32.5
$$

which leads to the following relation (16):

$$
\Delta G_{0}^{298}=G\left(A^{-}\right)-G(A H)-32.5
$$

Previous theoretical work on the prediction of acidity has shown that gradient-corrected functional and hybrid functionals such as B3LYP associated with 
bases $6-311+\mathrm{G}(\mathrm{d})$ and $6-311+\mathrm{G}(3 \mathrm{df}, 3 \mathrm{pd})$ lead to results in good agreement with the experimental data [45] [46] [47] [48]. This motivates our choice of the level of calculation implemented in this work.

\section{Results and Discussion}

The ketone-enol tautomeric equilibrium in the case of quinolin-4-one and the tautomeric structures which were the subject of this study are shown respectively in Figure 1 and Figure 2.

The performed calculations highlight the following parameters:

1) Thermodynamic parameters (Table 1);

2) The energies of boundaries molecular orbital and energetic gaps (Table 2);

3) Reactivity indices (Table 3);

4) The functions of Fukui (Table 4);

5) The deprotonation energies (Table 5).

\subsection{Thermodynamic Parameters and Relative Stability}

The calculated thermodynamic parameters are free enthalpies and enthalpies of formation. From these thermodynamic quantities, the reaction enthalpies and the equilibrium constants are determined. The order of relative stability of the tautomers is established from the enthalpy energies of formation of the different compounds. The values of the thermodynamic quantities calculated in gaseous phase and in DMF solution are gathered in Table 1.

Keq1 and Keq2 are respectively equilibrium constants in directions 1 and 2

Table 1. Enthalpy of formation, reaction enthalpy and equilibrium constants of tautomers of quinoline derivatives calculated at the B3LYP/6-311G (d) theory level.

\begin{tabular}{|c|c|c|c|c|c|}
\hline Tautomers & $\Delta_{\mathrm{f}} \mathrm{H}\left(\mathrm{Kcal} \mathrm{mol}^{-1}\right)$ & $\Delta_{\mathrm{r}} \mathrm{H}\left(\mathrm{Kcal} . \mathrm{mol}^{-1}\right)$ & equilibrium & $\mathrm{K}_{\mathrm{eq} 1}$ & $\mathrm{~K}_{\mathrm{eq} 2}$ \\
\hline \multicolumn{6}{|c|}{ Gas phase } \\
\hline $\begin{array}{c}\text { Q-4-one } \\
\text { Q-4-hydroxy }\end{array}$ & $\begin{array}{l}-299399.8 \\
-299392.9\end{array}$ & 6.957 & Q-4-one $\leftrightarrow$ Q-4-hydroxy & 0.982 & 1.018 \\
\hline $\begin{array}{c}\text { DMQ } \\
\text { DMHQ }\end{array}$ & $\begin{array}{l}-443115.7 \\
-443115.7\end{array}$ & 0.464 & $\mathrm{DMQ} \leftrightarrow \mathrm{DMHQ}$ & 0.997 & 1.003 \\
\hline $\begin{array}{c}\text { DBrQ } \\
\text { DBrHQ }\end{array}$ & $\begin{array}{l}-3529303.0 \\
-3529299.2\end{array}$ & 3.773 & $\mathrm{DBrQ} \leftrightarrow \mathrm{DBrHQ}$ & 0.989 & 1.011 \\
\hline \multicolumn{6}{|c|}{ DMF } \\
\hline $\begin{array}{c}\text { Q-4-one } \\
\text { Q-4-hydroxy }\end{array}$ & $\begin{array}{l}-299409.9 \\
-299394.8\end{array}$ & 14.680 & Q-4-one $\leftrightarrow$ Q-4-hydroxy & 0.997 & 1.003 \\
\hline $\begin{array}{c}\text { DMQ } \\
\text { DMHQ }\end{array}$ & $\begin{array}{l}-443121.4 \\
-443117.6\end{array}$ & 3.591 & $\mathrm{DMQ} \leftrightarrow \mathrm{DMHQ}$ & 0.989 & 1.011 \\
\hline $\begin{array}{c}\text { DBrQ } \\
\text { DBrHQ }\end{array}$ & $\begin{array}{l}-3529306.8 \\
-3529299.2\end{array}$ & 7.323 & $\mathrm{DBrQ} \leftrightarrow \mathrm{DBrHQ}$ & 0.98 & 1.021 \\
\hline
\end{tabular}


Table 2. Energies of HOMO, LUMO boundary orbitals and energy gaps of tautomers of quinolin-4-one derivatives calculated at B3LYP/6-311G (d).

\begin{tabular}{cccc}
\hline \multirow{2}{*}{ Tautomers } & HOMO $(\mathrm{eV})$ & LUMO $(\mathrm{eV})$ & $\Delta \mathrm{E}(\mathrm{eV})$ \\
\cline { 2 - 4 } & -6.248 & Gas phase \\
\hline Q-4-one & -6.295 & -1.355 & 4.893 \\
Q-4-hydroxy & -5.429 & -1.516 & 4.779 \\
DMQ & -5.462 & -0.827 & 4.603 \\
DMHQ & -6.303 & -0.964 & 4.498 \\
DBrQ & -6.435 & -1.844 & 4.459 \\
DBrHQ & & -2.049 & 4.387 \\
& -6.157 & & \\
Q-4-one & -6.050 & -1.488 & 4.669 \\
Q-4-hydroxy & -5.599 & -1.595 & 4.455 \\
DMQ & -5.628 & -1.145 & 4.453 \\
DMHQ & -6.305 & -1.238 & 4.389 \\
DBrQ & -6.458 & -1.879 & 4.427 \\
DBrHQ & & -2.041 & 4.417 \\
\hline
\end{tabular}

(Figure 1). The values of the equilibrium constants mentioned in Table 1 are approximately equal to 1 which indicates that the reaction is in its equilibrium domain. Experimental data have shown that the probable existence of a tautomer relationship could explain the failure of tetrahydroquinoline to be obtained from 5,8-dimethoxy-quinolin-4-one by Reetz conditions [17]. Equilibrium constancy calculations confirm this hypothesis. They highlight a tautomeric equilibrium relationship between different tautomers. For two given tautomers, the results show that the ketone forms (Q-4-one, DMQ, DBrQ) have the lowest formation enthalpy values (Table 1 ). These are therefore more stable than the enol forms. In the case of 5,8-dimethoxy-quinolin-4-one, the enthalpies of formation of tautomers have very similar values. Both ketone and enol forms have a very similar stability. The reaction enthalpies are all positive which means that the equilibrium reaction is an endothermic one.

\subsection{Chemical Reactivity}

\subsubsection{Theory of Frontier Molecular Orbitals}

Table 2 contains the energies of the HOMO LUMO boundary orbitals and the HOMO-LUMO energy gaps.

The energy gap values decrease in the DMF solvent (Table 2) compared with those obtained in the gas phase. The molecules are therefore more reactive in solution. The obtained values of the ketone tautomers are greater than those obtained with enols in the two areas. The ketone forms are less polarizable than tautomers ones. And they have low chemical reactivity with high kinetic stability compared to enol tautomers. The substituents on quinoline cause a decrease in 
the energy gap. The smallest energy gap is obtained with bromine. This substituent therefore increases the reactivity of quinolin-4-one. At the enol form level, the quinoline-4-one methoxylated has the lowest value of $\Delta \mathrm{E}$ which means that the methoxyl group leads to the most reactive enol form. We note however that among two tautomers, the different energy gaps are close to each other. This denotes that the tautomers reactivity is very closed to each other. This can explain the equivalence of $\mathrm{N}$ - and $\mathrm{O}$-benzylation yielding rates in the benzylation reaction of quinolin-4-one [17].

\subsubsection{Global Indices of Reactivity}

The study of the global reactivity of tautomers is based on the computation of global indices deduced from electronic properties. Global indices of the reactivity of studied tautomers are shown in Table 3.

According to these parameters, the chemical reactivity varies with the structure of the tautomers. Global softness $(S)$ values of ketonic tautomers are lower than enol ones, indicating that ketone tautomers are soft. Also, we note that ketones have their electronegativity values $(\chi)$ lower than those of enols; except (Q-4-one) in DMF (3.823 eV). They are therefore good donors of electrons. In terms of ketone forms, the brominated derivative has the greatest value of electronegativity. It is therefore the best electron acceptor compared to the methoxylated derivatives. These data show that the bromine atom contributes to increase this index of reactivity. Concerning the methoxyl substituent it causes a decrease in the value of the same parameter. In addition, electrophile index

Table 3. Ionization potential (IP, eV), electron affinity (EA, eV), chemical potential $(\mu$, $\mathrm{eV})$, chemical hardness $(\eta, \mathrm{eV})$, softness $\left(\mathrm{S}, \mathrm{eV}^{-1}\right)$ and overall electrophile index $(\omega, \mathrm{eV})$. of tautomers and some quinolin-4-one derivatives calculated at B3LYP/6-311G (d).

\begin{tabular}{cccccccc}
\hline \multirow{2}{*}{ Tautomers } & IP $(\mathrm{eV})$ & $\mathrm{EA}(\mathrm{eV})$ & $\mu(\mathrm{eV})$ & $\chi(\mathrm{eV})$ & $\mathrm{n}(\mathrm{eV})$ & $\mathrm{S}(\mathrm{eV})^{-1}$ & $\omega(\mathrm{eV})$ \\
\cline { 2 - 8 } & \multicolumn{7}{c}{ Gas phase } \\
\hline Q-4-one & 6.248 & 1.355 & -3.801 & 3.801 & 2.447 & 0.409 & 2.953 \\
Q-4-hydroxy & 6.295 & 1.516 & -3.905 & 3.905 & 2.390 & 0.418 & 3.191 \\
DMQ & 5.429 & 0.827 & -3.128 & 3.128 & 2.301 & 0.435 & 2.126 \\
DMHQ & 5.462 & 0.964 & -3.213 & 3.213 & 2.249 & 0.445 & 2.295 \\
DBrQ & 6.303 & 1.844 & -4.073 & 4.073 & 2.229 & 0.449 & 3.689 \\
DBrHQ & 6.435 & 2.049 & -4.242 & 4.242 & 2.193 & 0.456 & 4.102 \\
& & & & & & & \\
Q-4-one & 6.157 & 1.488 & -3.823 & 3.823 & 2.334 & 0.428 & 3.130 \\
Q-4-hydroxy & 6.050 & 1.595 & -3.822 & 3.822 & 2.228 & 0.449 & 3.279 \\
DMQ & 5.599 & 1.145 & -3.372 & 3.372 & 2.227 & 0.449 & 2.553 \\
DMHQ & 5.628 & 1.238 & -3.433 & 3.433 & 2.195 & 0.456 & 2.685 \\
DBrQ & 6.305 & 1.879 & -4.092 & 4.092 & 2.213 & 0.452 & 3.815 \\
DBrHQ & 6.458 & 2.041 & -4.250 & 4.250 & 2.208 & 0.453 & 4.088 \\
\hline
\end{tabular}


values of ketonic tautomers are lower than those of enol indicating that ketonic tautomers are less electrophilic.

\subsubsection{Fukui Functions}

The calculation of Fukui's functions was performed using Hirschfeld populations [49]. The results are summarized in Table 4. This calculation relates to all the atoms of the quinolin-4-one ring (Figure 1).

The calculated Fukui functions indicate positive values of $\Delta f$ at the $\mathrm{C} 2, \mathrm{C} 3, \mathrm{C} 4$, C5, C7 and C8 carbon atoms in all molecules (Table 4). These atoms are electrophilic sites. A nucleophilic attack in these molecules will happen on $\mathrm{C} 4$ and $\mathrm{C} 5$ carbons which have the highest values of $\Delta f$. Failure of $\mathrm{C} 4$ carbon dimethylation and reduction of the $\mathrm{C} 2=\mathrm{C} 3$ double bond of the quinoline ring may be due to the fact that these atoms are nucleophilic sites. They are therefore favorable to an electrophilic attack. The N1, C8, C9 and O11 atoms have a negative value of $\Delta f$. These atoms are nucleophilic sites. They are susceptible to electrophilic attack. The nitrogen atom $\mathrm{N} 1$ has the highest negative value of $\Delta f$ which means that an electrophilic attack will happen preferentially on this atom. The probable sites of nucleophilic and electrophilic attack are the same in all the molecules. The substitution does not modify the reactivity sites of these molecules.

\subsection{Prediction of Acidity of Tautomers of Quinoline-4-one Derivatives}

Gibbs free energies of deprotonation $\left(\Delta G_{0}^{298}\right)$ are calculated in the gas phase at B3LYP/6-311+G (d). The values of this thermodynamic quantity are grouped together in Table 5.

The grouped data in Table 5 show an increase in the free enthalpy of the deportation reaction with the methoxyl group. This energy decreases with bromine.

Table 4. Calculated Fukui functions in gas phase at B3LYP/6-311 + G (d) ketone forms.

\begin{tabular}{|c|c|c|c|c|c|c|c|c|c|}
\hline \multirow{2}{*}{ Atomes } & \multicolumn{3}{|c|}{ Q-4-one } & \multicolumn{3}{|c|}{ DMQ } & \multicolumn{3}{|c|}{$\mathrm{DBrQ}$} \\
\hline & $f$ & $f^{\prime}$ & $\Delta f$ & $f$ & $f$ & $\Delta f$ & $f$ & $f^{*}$ & $\Delta f$ \\
\hline N1 & 0.284 & -0.072 & -0.356 & 0.243 & -0.096 & -0.339 & 0.159 & -0.198 & -0.357 \\
\hline $\mathrm{C} 2$ & -0.205 & -0.074 & 0.131 & -0.102 & 0.042 & 0.144 & -0.208 & -0.069 & 0.139 \\
\hline $\mathrm{C} 3$ & 0.051 & 0.141 & 0.089 & -0.051 & 0.035 & 0.086 & -0.049 & 0.047 & 0.096 \\
\hline $\mathrm{C} 4$ & -0.224 & 0.088 & 0.312 & -0.123 & 0.146 & 0.269 & -0.219 & 0.145 & 0.364 \\
\hline C5 & -0.153 & 0.162 & 0.315 & -0.156 & 0.175 & 0.331 & -0.151 & 0.174 & 0.325 \\
\hline C6 & -0.103 & -0.124 & -0.81 & -0.106 & -0.189 & -0.083 & -0.981 & -0.167 & -0.814 \\
\hline C7 & -0.229 & -0.090 & 0.139 & -0.113 & 0.054 & 0.167 & -0.135 & 0.033 & 0.168 \\
\hline $\mathrm{C} 8$ & -0.021 & 0.220 & 0.241 & -0.058 & 0.223 & 0.281 & -0.065 & 0.219 & 0.284 \\
\hline C9 & -0.009 & -0.038 & -0.029 & -0.007 & -0.028 & -0.021 & 0.006 & -0.017 & -0.023 \\
\hline $\mathrm{C} 10$ & 0.062 & -0.020 & -0.082 & -0.060 & -0.024 & -0.084 & -0.080 & -0.009 & -0.089 \\
\hline $\mathrm{C} 11$ & 0.022 & -0.127 & -0.149 & 0.065 & -0.114 & -0.179 & 0.078 & -0.103 & -0.181 \\
\hline
\end{tabular}


Table 5. Free enthalpies of formation and deprotonation of quinoline-4-one tautomers calculated in the gas phase at B3LYP/6-311+G (d) level.

\begin{tabular}{|c|c|c|c|}
\hline \multirow{2}{*}{ Tautomers } & \multicolumn{2}{|c|}{$\Delta G_{0}^{298}(\mathrm{Kcal} / \mathrm{mol})$} & \multirow{2}{*}{$\Delta G_{0}^{298} \quad(\mathrm{Kcal} / \mathrm{mol})$} \\
\hline & $\mathrm{AH}$ & Deprotonated molecule $\mathrm{A}^{-}$ & \\
\hline Q-4-one $\left(\mathrm{N}^{1}-\mathrm{H}\right)$ & -299422.21 & -299091.11 & 324.81 \\
\hline $\mathrm{Q}$-4-one $\left(\mathrm{O}^{11}-\mathrm{H}\right)$ & -299415.34 & -299091.11 & 317.94 \\
\hline DMQ $\left(\mathrm{N}^{1}-\mathrm{H}\right)$ & -443145.23 & -442806.26 & 332.68 \\
\hline $\operatorname{DMQ}\left(\mathrm{O}^{11}-\mathrm{H}\right)$ & -443144.01 & -442806.26 & 331.46 \\
\hline $\operatorname{DBrQ}\left(\mathrm{N}^{1}-\mathrm{H}\right)$ & -3529228.80 & -3528905.10 & 317.41 \\
\hline $\operatorname{DBrQ}\left(\mathrm{O}^{11}-\mathrm{H}\right)$ & -3529224.55 & -3528905.11 & 313.15 \\
\hline
\end{tabular}

According to these data, we can establish the increasing order of the studied molecules by taking into account the free energy of deprotonation $\left(\Delta G_{0}^{298}\right)$ at $298 \mathrm{~K}$ : This order is: $\Delta \mathrm{G}\left[\mathrm{DBrQ}\left(\mathrm{O}^{11}-\mathrm{H}\right)\right]<\Delta \mathrm{G}\left[\mathrm{DBrQ}\left(\mathrm{N}^{1}-\mathrm{H}\right)\right]<\Delta \mathrm{G}[\mathrm{Q}-4$-one $\left.\left(\mathrm{O}^{11}-\mathrm{H}\right)\right]<\Delta \mathrm{G}\left[\mathrm{Q}-4\right.$-one $\left.\left(\mathrm{N}^{1}-\mathrm{H}\right)\right]<\Delta \mathrm{G}\left[\right.$ DMQ $\left.\left(\mathrm{O}^{11}-\mathrm{H}\right)\right]<\Delta \mathrm{G}\left[\mathrm{DMQ}\left(\mathrm{N}^{1}-\mathrm{H}\right)\right]$. Bromine contributes to reducing the free energies of deprotonation of the nitrogen and oxygen atoms while the methoxyl group increases the same thermodynamic parameter on the same atoms. These results indicate that a deprotonation of the $\mathrm{N}^{1}-\mathrm{H}$ nitrogen in the case of brominated quinolin-4-one will be easier than that of the nitrogen $\left(\mathrm{N}^{1}-\mathrm{H}\right)$ of the methoxylated derivative. Work has shown that there is an inverse relationship between the amplitude of $\Delta \mathrm{G}$ and the strength of the acid. The lower the value of $\Delta \mathrm{G}$, the more acidic the site is [41] [42] [43] [44]. In this way, the nitrogen atoms $\mathrm{N}^{1}-\mathrm{H}$ and oxygen $\mathrm{O}^{11}-\mathrm{H}$ in the brominated compounds are more acidic. These sites are less acidic in the methoxylated derivatives. Through the analysis of these free energies of deprotonation, we can establish the following decreasing order of studied molecules according to acidity: DBrQ $\left(\mathrm{O}^{11}-\mathrm{H}\right)>\mathrm{DBrQ}\left(\mathrm{N}^{1}-\mathrm{H}\right)>\mathrm{Q}$-4-one $\left(\mathrm{O}^{11}-\mathrm{H}\right)>\mathrm{Q}$-4-one $\left.\left(\mathrm{N}^{1}-\mathrm{H}\right)\right]>$ DMQ $\left(\mathrm{O}^{11}-\mathrm{H}\right)>$ DMQ $\left(\mathrm{N}^{1}-\mathrm{H}\right)$. For a given quinoline, the deprotonation energy of the hydroxyl $\left(\mathrm{O}^{11}-\mathrm{H}\right)$ of the enol form is lower than that of the nitrogen $\left(\mathrm{N}^{1}-\mathrm{H}\right)$ of the ketone form.

\section{Conclusion}

The results of this theoretical study on the quinoline-4-one derivatives have shown that the ketone forms are therefore more stable than the enol ones. Experimental data have shown that the probable existence of a tautomerism can explain the failure to obtain tetrahydroquinoline from 5,8-dimethoxy-quinolin-4-one. Equilibrium constancy calculations confirmed this hypothesis. They highlight equilibrium relationship between different tautomers which is an endothermic reaction. Reactivity analysis from boundary molecular orbital theory has also shown that bromine $(\mathrm{Br})$ increases the reactivity of quinoline. On the other hand, brominated quinolin-4-one is more reactive than its methoxylated analogues. Calculation of Fukui functions showed that $\mathrm{C} 2$ and $\mathrm{C} 3$ carbon atoms are electro- 
philic sites. This fact is a possible explanation for the failure of the reduction of the double bond in quinolin-4-one. These results indicate that deprotonation of $\mathrm{N}^{1}-\mathrm{H}$ nitrogen in the case of brominated quinoline would be easier than that of nitrogen $\left(\mathrm{N}^{1}-\mathrm{H}\right)$ of the methoxylated derivatives. The results predict a higher acidity of the $\mathrm{N}^{1}-\mathrm{H}$ and $\mathrm{O}^{11}-\mathrm{H}$ sites in the case of the brominated compounds. A theoretical study of the reaction mechanism of the $\mathrm{N}^{1}-\mathrm{H}$ nitrogen deprotonation reaction of these molecules is envisaged in order to bring more precision to this first conclusion.

\section{Acknowledgements}

The authors would like to thank Lamoussa Ouattara for his contribution to the realization of this work.

\section{References}

[1] Belot, A., Grosclaude, P., Bossard, N., Jougla, E. and Benhamou, E. (2008) Cancer Incidence and Mortality in France over the period 1980-2005. Revue d'épidémiologie et de santé publique, 56, 159-175.

https://doi.org/10.1016/j.respe.2008.03.117

[2] Kumar, A., Chelvam, V., Sakkarapalayam, M., Li, G.P., Sanchez-Cruz, N.S., Piñero, P.S., Low, P.S. and Alegria, A.E. (2016) Synthesis and Evaluation of Folate-Conjugated Phenanthraquinones for Tumor-Targeted Oxidative Chemotherapy. Open Journal of Medicinal Chemistry, 6, 1-17.

[3] Apel, K. and Hirt, H. (2004) Reactive Oxygen Species: Metabolism, Oxidative Stress, and Signal Transduction. Annual Review of Plant Biology, 55, 373-399. https://doi.org/10.1146/annurev.arplant.55.031903.141701

[4] Fieser, L.F. (1929) The Reduction Potentials of Various Phenanthrenequinones. Journal of the American Chemical Society, 51, 3101-3111. https://doi.org/10.1021/ja01385a032

[5] Shinkre, B.A., Raisch, K.P., Fan, L. and Velu, S.E. (2007) Analogs of the Marine Alkaloid Makaluvamines: Synthesis, Topoisomerase II Inhibition, and Anticancer Activity. Bioorganic \& Medicinal Chemistry Letters, 17, 2890-2893. https://doi.org/10.1016/j.bmcl.2007.02.065

[6] Shinkre, B.A., Raisch, K.P., Fan, L. and Velu, S.E. (2008) Synthesis and Antiproliferative Activity of Benzyl and Phenethyl Analogs of Makaluvamines. Bioorganic \& Medicinal Chemistry, 16, 2541-2549. https://doi.org/10.1016/j.bmc.2007.11.051

[7] Ezell, S.J., Li, H., Xu, H., Zhang, X., Gurpinar, E., Zhang, X., Rayburn, E.R., Sommers, C.I., Yang, X., Velu, S.E., Wang, W. and Zhang, R. (2010) Preclinical Pharmacology of BA-TPQ, a Novel Synthetic Iminoquinone Anticancer Agent. Marine Drugs, 8, 2129-2141. https://doi.org/10.3390/md8072129

[8] Hoang, H., LaBarbera, D., Mohammed, K., Ireland, C. and Skibo, E. (2007) Synthesis and Biological Evaluation of Imidazoquinoxalinones, Imidazole Analogues of Pyrroloiminoquinonemarine Natural Products. Journal of Medicinal Chemistry, 50, 4561-4571. https://doi.org/10.1021/jm0700870

[9] Barrows, L.R., Radisky, D.C., Copp, B.R., Swaffar, D.S., Kramer, R.A., Warters, R.L. and Ireland, C.M. (1993) Makaluvamines, Marine Natural Products, Are Active Anti-Cancer Agents and DNA Topo II Inhibitors. Anti-Cancer Drug Design, 8, 
333-347.

[10] Delfourne, E. (2008) Analogues of Marine Pyrroloiminoquinone Alkaloids: Synthesis and Antitumor Properties. Anticancer Agents. Journal of Medicinal Chemistry, 8, 910-916. https://doi.org/10.2174/187152008786847710

[11] Hajra, S., Maji, B. and Karmakar, A. (2005) Lewis Acid Catalyzed Intramolecular Halo-Arylation of Tethered Alkenes Using $N$-halosuccinimide (NXS) as the Halogen Source: A General Method for the Synthesis of Chromanones, Chromans, Quinolones, Tetrahydroquinolines and Tetralins. Tetrahedron Letters, 46, 8599-8603. https://doi.org/10.1016/j.tetlet.2005.09.170

[12] Antunes, E.M., Beukes, D.R., Kelly, M., Samaai, T., Barrows, L.R., Marshall, K.M., Sincich, C. and Davies-Coleman, M.T. (2004) Cytotoxic Pyrroloiminoquinones from Four New Species of South African Latrunculid Sponges. Journal of Natural Products, 67, 1268-1276. https://doi.org/10.1021/np034084b

[13] Monks, A., Scuderio, D.A., Skehan, P., Shoemaker, R.H., Paull, K.D., Hose, V.C., Langley, J., Cronise, P., Vaigro-Wolff, A., Grey-Goodrich, M., Campball, H. and Boyd, M.R. (1991) Feasibility of a High-Flux Anticancer Drug Screen Using a Diverse Panel of Cultured Human Tumor Cell Lines. Journal of the National Cancer Institute, 83, 757-766. https://doi.org/10.1093/jnci/83.11.757

[14] Clerici, A. and Porta, O. (1990) Arylative Amination of Aldehydes Promoted by Aqueous Titanium Trichloride. Tetrahedron Letters, 31, 2069-2072. https://doi.org/10.1016/S0040-4039(00)88918-2

[15] Kitahara, Y., Tamura, F., Nishimura, M. and Kubo, A. (1998) Synthesis of Meridine, Cystodamine, and Related Compounds Including Iminoquinolinequinone Structure. Tetrahedron, 54, 8421-8432. https://doi.org/10.1016/S0040-4020(98)00463-3

[16] Marcos, A., Pedregal, C. and Avendaño, C. (1995) Synthesis of 1,5- and 1,8-Diazaanthraquinones by Reaction of Aminoquinolinequinones with $\beta$-dielectrophiles. Tetrahe dron, 51, 1763-1774. https://doi.org/10.1016/0040-4020(94)01048-5

[17] Reetz, M.T. and Seitz, T. (1987) Regio-und Stereoselektive Carbosulfenylierung von Olefinen. Angewandte Chemie, 99, 1081-1082. https://doi.org/10.1002/ange.19870991034

[18] Bouclé, S. (2010) Synthèse d'analogues d'alcaloïdes marins à potentiel anti-tumoral. Thèse de Doctorat, Université Francois-Rabelais de Tours.

[19] Kurt, M., Sertbakan, T.R. and Ozduran, M. (2008) Spectrochim, an Experimental and Theoretical Study of Molecular Structure and Vibrational Spectra of 3- and 4-Pyridineboronic Acid Molecules by Density Functional Theory Calculations. Spectrochimica Acta Part A: Molecular and Biomolecular Spectroscopy, 70, 664-673. https://doi.org/10.1016/j.saa.2007.08.019

[20] Ravikumar, C., Joe, I.H. and Jayakumar, V.S. (2008) Charge Transfer Interactions and Nonlinear Optical Properties of Push-Pull Chromophore Benzaldehyde Phenylhydrazone: A Vibrational Approach. Chemical Physics Letters, 460, 552-558. https://doi.org/10.1016/j.cplett.2008.06.047

[21] Frisch, M.J., Trucks, G.W., Schlegel, H.B., et al. (2003) Gaussian 03, Revision A.1. Gaussian Inc., Pittsburgh.

[22] Kohn, W. and Sham, L. (1965) Self-Consistent Equations Including Exchange and Correlation Effects. Physical Review, 140, 1133-1138. https://doi.org/10.1103/PhysRev.140.A1133

[23] Becke, A.D. (1997) Density-Functional Thermochemistry. V. Systematic Optimization of Exchange-Correlation Functionals. The Journal of Chemical Physics, 107, 8554-8560. https://doi.org/10.1063/1.475007 
[24] Bauernschmitt, R. and Ahlrichs, R. (1996) Stability Analysis for Solutions of the Closed Shell Kohn-Sham Equation. The Journal of Chemical Physics, 104, 9047-9052. https://doi.org/10.1063/1.471637

[25] Canses, E., Mennucci, B. and Tomasi, J. (1997) A New Integral Equation Formalism for the Polarizable Continuum Model: Theoretical Background and Applications to Isotropic and Anisotropic Dielectrics. The Journal of Chemical Physics, 107, 3032-3041. https://doi.org/10.1063/1.474659

[26] Tomasi, J. and Persico, M. (1994) Molecular Interactions in Solution: An Overview of Methods Based on Continuous Distributions of the Solvent. Chemical Reviews, 94, 2027-2094. https://doi.org/10.1021/cr00031a013

[27] Fujimoto, H. and Fukui, K. (1972) Molecular Orbital Theory of Chemical Reactions. Advances in Quantum Chemistry, 6, 177-201.

https://doi.org/10.1016/S0065-3276(08)60545-6

[28] Belletête, M., Morin, J.F., Leclerc, M. and Durocher, G. (2005) A Theoretical, Spectroscopic, and Photophysical Study of 2,7-Carbazolenevinylene-Based Conjugated Derivatives. The Journal of Physical Chemistry A, 109, 6953-6959.

https://doi.org/10.1021/jp051349h

[29] Jun-ichi, A. (1999) Reduced HOMO-LUMO Gap as an Index of Kinetic Stability for Polycyclic Aromatic Hydrocarbons. The Journal of Physical Chemistry A, 103, 7487-7495. https://doi.org/10.1021/jp990092i

[30] Morell, C., Grand, A. and Toro-Labbé, A. (2005) A New Dual Descriptor for Chemical Reactivity. The Journal of Physical Chemistry A, 109, 205-212.

https://doi.org/10.1021/jp046577a

[31] Bultinck, P., Clarisse, D., Ayers, P.W. and Carbo-Dorca, R. (2011) The Fukui Matrix: A Simple Approach to the Analysis of the Fukui Function and Its Positive Character. Physical Chemistry Chemical Physics, 13, 6110-6115. https://doi.org/10.1039/c0cp02268c

[32] Melin, J., Ayers, P.W. and Ortiz, J.V. (2007) Removing Electrons Can Increase the Electron Density: A Computational Study of Negative Fukui Functions. The Journal of Physical Chemistry A, 111, 10017-10019. https://doi.org/10.1021/jp075573d

[33] Padmanabhan, J., Parthasarathi, R., Elango, M., Subramanian, V., Krishnamoorthy, B.S., Gutierrez-Oliva, S., Toro-Labbe, A., Roy, D.R. and Chattaraj, P.K. (2007) Multiphilic Descriptor for Chemical Reactivity and Selectivity. The Journal of Physical Chemistry, 111, 9130-9138. https://doi.org/10.1021/jp0718909

[34] Parr, R.G., Donnelly, R.A., Levy, M. and Palke, W.E. (1978) Electronegativity: The Density Functional Viewpoint. The Journal of Chemical Physics, 68, 3801-3807. https://doi.org/10.1063/1.436185

[35] Mulliken, R.S. (1934) A New Electroaffinity Scale: Together with Data on Valence States and on Ionization Potential and Electron Affinities. The Journal of Chemical Physics, 2, 782-793. https://doi.org/10.1063/1.1749394

[36] Zhou, Z. and Parr, R.G. (1989) New Measures of Aromaticity-Absolute Hardness and Relative Hardness. Journal of the American Chemical Society, 111, 7371-7379. https://doi.org/10.1021/ja00201a014

[37] Parr, R.G. and Gazquez, J.L. (1993) Hardness Functional. The Journal of Physical Chemistry, 97, 3939-3940. https://doi.org/10.1021/j100118a003

[38] Pearson, R.G. (1987) Recent Advances in the Concept of Hard and Soft Acids and Bases. Journal of Chemical Education, 64, 561-567.

https://doi.org/10.1021/ed064p561 
[39] Parr, R.G., Szentpály, L.V. and Liu, S. (1999) Electrophilicity Index. Journal of the American Chemical Society, 121, 1922-1924. https://doi.org/10.1021/ja983494x

[40] Koopmans, T. (1934) Über die zuordnung von wellen funktionen und eigenwerten zu den einzelnen elektronen eines atom. Physica, 1, 104-113. https://doi.org/10.1016/S0031-8914(34)90011-2

[41] Lim, C., Bashford, D. and Karplus, M. (1991) Absolute pKa Calculations with Continuum Dielectric Methods. The Journal of Physical Chemistry, 95, 5610-5620. https://doi.org/10.1021/j100167a045

[42] Topol, I.A., Tawa, G.J., Burt, S.K. and Rashin, A.A. (1997) Calculation of Absolute and Relative Acidities of Substituted Imidazoles in Aqueous Solvent. The Journal of Physical Chemistry A, 101, 10075-10081. https://doi.org/10.1021/jp9723168

[43] Remko, M. (2003) Theoretical Study of Molecular Structure and Gas-Phase Acidity of Some Biologically Active Sulfonamides. The Journal of Physical Chemistry A, 107, 720-725. https://doi.org/10.1021/jp026980m

[44] Assoma, A.B., Bede, A.L., Kone, M. and N’Guessan, Y.T. (2010) Theoretical Study of Stability, Tautomerism, Equilibrium, Constants (pkT), Activation Energies and Acidity of 6-Thioxanthine in Gas and Aqueous Phase by the Ab Initio Method and Functional Density Theory Calculations. European Journal of Scientific Research, 44, 337-354.

[45] Klicić, J.J., Friesner, R.A., Shi-Yi, L. and Wayne, C.G. (2002) Accurate Prediction of Acidity Constants in Aqueous Solution via Density Functional Theory and Self-Consistent Reaction Field Methods. The Journal of Physical Chemistry A, 106, 1327-1335. https://doi.org/10.1021/jp012533f

[46] Keith, J.A. and Carter, E.A. (2012) Quantum Chemical Benchmarking, Validation, and Prediction of Acidity Constants for Substituted Pyridinium Ions and Pyridinyl Radicals. Journal of Chemical Theory and Computation, 8, 3187-3206. https://doi.org/10.1021/ct300295g

[47] Remko, M. and von der Lieth, C.W. (2004) Theoretical Study of Gas-Phase Acidity, $\mathrm{p} K_{\mathrm{a}}$, Lipophilicity, and Solubility of Some Biologically Active Sulfonamides. Bioorganic \& Medicinal Chemistry, 12, 5395-5403. https://doi.org/10.1016/j.bmc.2004.07.049

[48] Vianello, R. and Maksić, Z.B. (2005) High Acidity of Polycyano AzatriquinanesTheoretical Prediction by the DFT Calculations. Tetrahedron Letters, 46, 3711-3713. https://doi.org/10.1016/j.tetlet.2005.03.142

[49] Roy, R.K. (1999) On Non-Negativity of Fukui Function Indices. The Journal of Chemical Physics, 110, 8236-8245. https://doi.org/10.1063/1.478792 